\title{
Basic Research Articles in the Journal of the Korean Society of Plastic and Reconstructive Surgeons from 1974 to 2011
}

Jong Won Rhie, MD, PhD

Associate Editor, Archives of Plastic Surgery

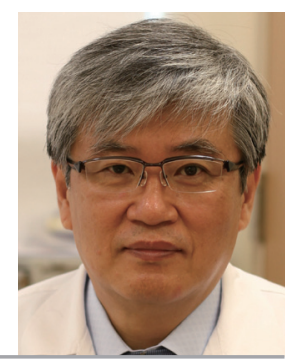

This editorial is an overview of the articles published in the history of the Journal of the Korean Society of Plastic and Reconstructive Surgeons (JKSPRS), the antecedent of the Archives of Plastic Surgery (APS), since its first issue in 1974. The main role of a scientific journal should be to deliver cutting edge information and update readers with the latest reports and articles within its diverse field of interest. JKSPRS has been providing its readers with an abundance of articles, not only in the form of clinical reports and studies, but also as basic research articles, related to plastic and reconstructive surgery. The phrase "Plastic Surgery" may mislead some to assume the journal to be a clinically oriented paper, but the numerous research topics it encompasses prove otherwise. This diversity in clinical and basic research studies in the journal enhances its status as a comprehensive concentration of knowledge in the field of plastic and reconstructive surgery.

This article focuses on the basic research studies published in the 35-year history of JKSPRS, the antecedent of APS, and categorizes these by time period, analyzing the proportion that basic research has occupied. The term "basic research article" is defined here as those studies based on procedures performed in the laboratory, such as cell cultures, animal studies, or anatomical measurements. Any studies based on clinical procedures or experiences, or clinical studies involving patients were not classified as basic research.

All articles published in the JKSPRS from its first issue in 1974 to 2011 were analyzed [1], and for convenience's sake, each decade has been termed by its distinguishing characteristics: the developmental period from 1974 to 1985, the growth period from then on to 1995 , the maturation period thereafter to 2005, and the transition period consisting of the last 6 years until 2011.

\section{THE DEVELOPMENTAL PERIOD (1974-1985)}

The Korean Society of Plastic and Reconstructive Surgeons (KSPRS) was first established in 1966, and the premier issue of its official journal was published in 1974 under the name the Journal of the Korean Society of Plastic and Reconstructive Surgeons (Fig. 1). This issue raised the curtain with an article entitled "The effect of antimacrophage serum on the survival of skin allograft" [2]. The following study, "Experimental studies on burn toxin" [3] was an experimental paper also, signaling that basic research was to be a fundamental component of this journal. Of the total of 495 articles published during the first decade after its birth (until 1985), 121 articles were experimental studies, comprising 24 percent. The topics included the following: microvascular circulation and blood vessels in 23 articles, wound healing in 22 articles, flap physiology and skin grafts in 18 articles, 16 anatomical studies and 10 morphometric studies, and others based on bone, nerve and tendon healing histology (Fig. 2).

\section{THE GROWTH PERIOD (1986-1995)}

During the decade following the mid 1980s, the number of published articles exponentially increased to triple that of the previous decade, totaling 1,496 articles. This is probably a consequence of the flourishing activities of the Society, which led to an increase in the number of its members. A sum of 304 basic research articles was published, constituting 20 percent of its

Copyright $($ C 2012 The Korean Society of Plastic and Reconstructive Surgeons

This is an Open Access article distributed under the terms of the Creative Commons Attribution Non-Commercial License (http://creativecommons.org/

licenses/by-nc/3.0/) which permits unrestricted non-commercial use, distribution, and reproduction in any medium, provided the original work is properly cited.

www.e-aps.org 
Fig. 1. The first issue of the Journal of the Korean Society of Plastic and Reconstructive Surgeons, published in 1974

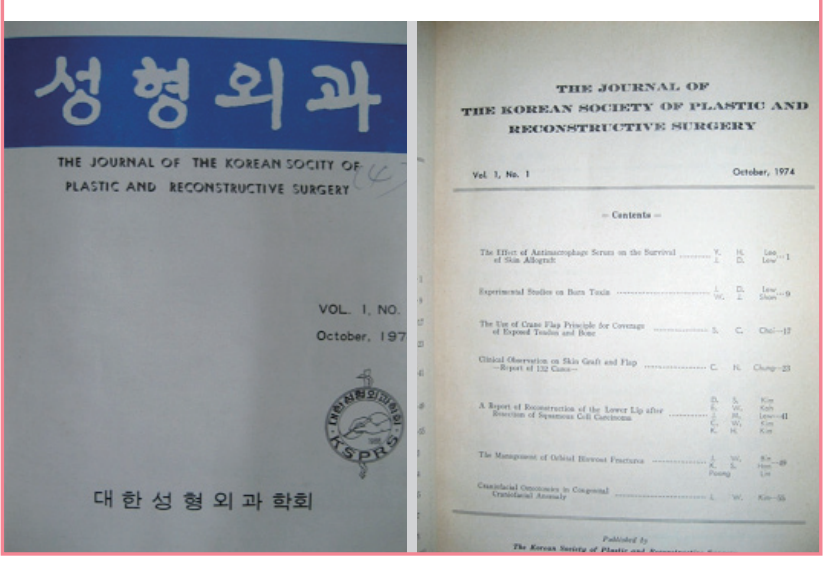

Fig. 2. The developmental period (1974-1985)

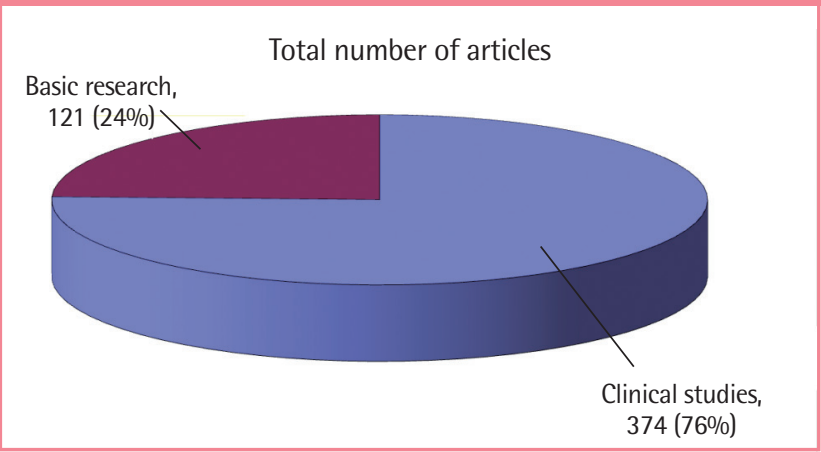

Fig. 3. The growth period (1986-1995)

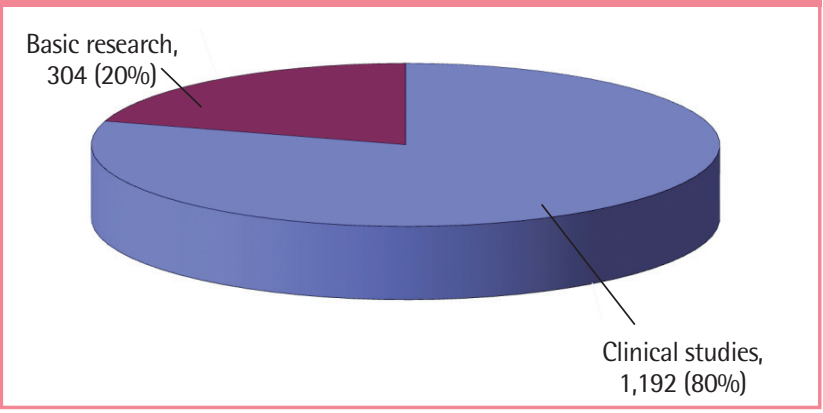

total content. Over $50 \%$ of the subjects addressed during this period overlapped with those of the previous decade: microvascular circulation hemodynamics and flaps, flap reconstruction, wound healing, bone, cartilage, and tendons. This decade witnessed a major growth spurt in the history of the field of plastic and reconstructive surgery (Fig. 3).

\section{THE MATURATION PERIOD (1996- 2005)}

There was a gentle increase in publications during this decade, and 1,600 articles were published. Of these 330 were basic
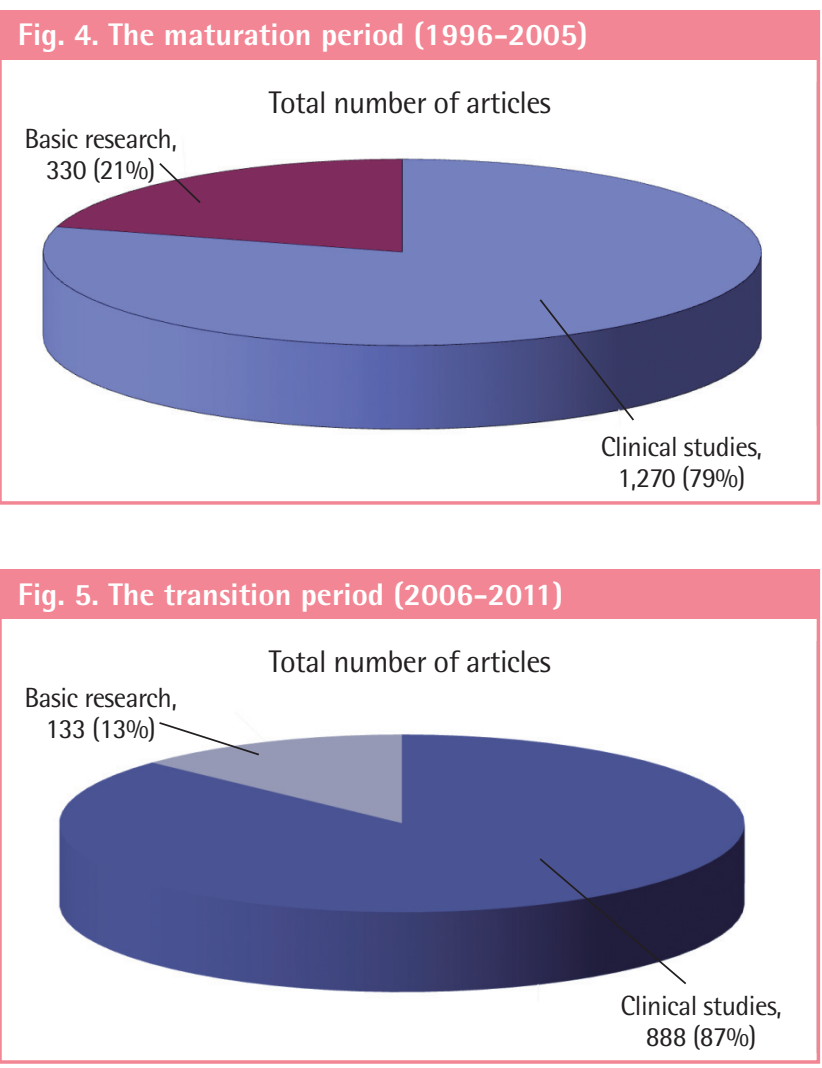

research articles, maintaining a proportion of $21 \%$ of the total, similar to the previous decade. A majority of the 112 articles were based on wound healing and cell culture experiments, these comprising a third of the total number of basic research papers, and in the latter half of this period, most studies involved cell culture in fat tissue and tissue engineering (Fig. 4).

\section{THE TRANSITION PERIOD (2006- 2011)}

The number of annual publications has been fairly consistent during the 6 years between 2006 and 2011, with a total of 1,021 articles. Of these, there were 133 basic research articles, which comprised a conspicuously lower $13 \%$ of the total. This decrease in proportion is thought to be mainly due to the increase in aesthetic clinical reports, progress in clinical aspects of plastic surgery, and an emphasis on Science Citation Index (SCI) journal submissions. During this period, the faculty performance evaluation system was introduced and initiated in all universities in Korea, and this assessment system has led to an unprecedented bias toward SCI journals. As most authors are professors or faculty at universities, JKSPRS, as a non-SCI journal, was inevitably put at a palpable disadvantage, and the rush toward SCI journal submission has resulted in a lower submission rate. This inclination is a consequence of a national change in the educa- 
tion evaluation system, and will continue in the future. Therefore, investing our efforts in receiving recognition as a SCI level journal is of the utmost importance (Fig. 5).

\section{THE EVOLUTION OF RESEARCH TOPICS}

If we take a look at the progression in study subject trends, the first 10 years has seen most papers focused on flap survival through medication or the delay procedure, and factors affecting the success rate of microsurgery and vessel anastomosis. Articles in the next decade involved flap reperfusion injury, an increase in flap survival using prostaglandin, hyperbaric oxygen treatment, studies in wound healing using growth factors, and changes in skin tissue after application of tissue expanders, which were introduced during this period. In the maturation decade after 1995, studies on factors enhancing wound healing, fat grafts and various synthetic fillers, and bone regeneration were mainstream. During the late 1990s, tissue engineering and stem cell studies began to be reported. This was an extension of the tissue engineering studies that began in the early 1990s in the United States. Research involving tissue engineering, biomaterial technology, and biology fused with tissue engineering techniques spread rapidly into Korea, and numerous studies integrating clinical medicine with engineering were reported by the late 1990s. Translation research, connecting embryonic stem cell studies with regenerative medicine, also came into the spotlight in the early 90 s, followed by the report that a major source of adult stem cells was adipose tissue. Fat tissue was an area that many plastic surgeons were familiar with through common procedures like fat grafts, and adipose-derived stem cells became a hot issue resulting in an abundance of studies.

After the decade of the mid 2000s, during the transition period, development in aesthetic surgical techniques accelerated, and microsurgery became more widespread, followed by a boom in anatomical studies on various perforators. Research involving adipose-derived stem cells, material easily obtained through liposuction, and its many functions, has led to the application of stem cells as cell therapy products. These products have been introduced as a treatment modality in chronic wound healing, and preclinical trials and clinical tests have been reported.

\section{PROPOSAL}

The undeniable advantage of basic research articles is that they are all original articles, and as such, data from these articles may be cited in other studies, increasing the impact factor of the journal. In the past, these research articles were actually submitted to an overseas journal first, then resubmitted to JKSPRS, a journal in the Korean language only, duplicate submission being the common practice. However, as the internet has allowed easy access to most publications, and as the Korean Association of Medical Journal Editors has reinforced its ethical standards, plagiarism or duplicate publication, salami publishing, and imalas have come to be viewed as unethical and inexcusable in academic societies both Korean and abroad. Institutional Review Board approved documents have become mandatory as a method of authentication. In basic research studies, the method and process that the researchers use to obtain results is receiving more attention in the validation process. Journals must scrutinize and evaluate the experimental log, and review how adequate the statistical analysis is. Reinforced authentication through such assessment protocols is necessary for quality control, and may be the shortcut to becoming a more renowned journal. However, due to plastic surgery's issues with privacy and photograph rights, author limitations (the author must be a member of KSPRS), its limited reader population, and other restrictive regulations, the Society's journal has found its low impact factor to be a tough obstacle in its path toward becoming an SCI class journal. At this important turning point, where we have outgrown the previous JKSPRS to convert into the Archives of Plastic Surgery, opening doors for submission from diverse fields, and adopting an open access system for a wider population of readers will provide us with a sturdy foundation on which to establish a high quality journal.

\section{REFERENCES}

1. The Korean Society of Plastic and Reconstructive Surgeons [Internet]. Seoul: The Society; c2006 [cited 2012 Feb 27]. Available from http://www.plasticsurgery.or.kr/.

2. Lee YH, Lew JD. The effect of antimacrophage serum on the survival of skin allograft. J Korean Soc Plast Reconstr Surg 1974;1:1-8.

3. Lew JD, Sohn WJ. Experimental studies on burn toxin. J Korean Soc Plast Reconstr Surg 1974;1:9-16.

\footnotetext{
Correspondence: Jong Won Rhie

Department of Plastic Surgery, Seoul St. Mary's Hospital, The Catholic University of Korea School of Medicine, 222 Banpo-daero, Seocho-gu, Seoul 137-701, Korea

Tel: +82-2-2258-6142, Fax: +82-2-594-7230, E-mail: rhie@ catholic.ac.kr

No potential conflict of interest relevant to this article was reported.

Received: 27 Feb 2012 • Revised: 3 Mar 2012 • Accepted: 4 Mar 2012

pISSN: 2234-6163 • elSSN: 2234-6171

http://dx.doi.org/10.5999/aps.2012.39.2.91 • Arch Plast Surg 2012;39:91-93
} 